\title{
Calendar age and puberty-related development of regional gray matter volume and white matter tracts during adolescence
}

\author{
Ayaka Ando ${ }^{1} \cdot$ Peter Parzer $^{2} \cdot$ Michael Kaess $^{3,4} \cdot$ Susanne Schell ${ }^{2} \cdot$ Romy Henze $^{5,6,7} \cdot$ Stefan Delorme ${ }^{8}$. \\ Bram Stieltjes $^{8,9} \cdot$ Franz Resch $^{2} \cdot$ Romuald Brunner $^{10} \cdot$ Julian Koenig $^{1,3}$ (B)
}

Received: 18 December 2019 / Accepted: 22 December 2020 / Published online: 20 January 2021

(c) The Author(s) 2021

\begin{abstract}
Background Adolescence is a critical time for brain development. Findings from previous studies have been inconsistent, failing to distinguish the influence of pubertal status and aging on brain maturation. The current study sought to address these inconsistencies, addressing the trajectories of pubertal development and aging by longitudinally tracking structural brain development during adolescence.

Methods Two cohorts of healthy children were recruited (cohort 1: 9-10 years old; cohort 2: 12-13 years old at baseline). MRI data were acquired for gray matter volume and white matter tract measures. To determine whether age, pubertal status, both or their interaction best modelled longitudinal data, we compared four multi-level linear regression models to the null model (general brain growth indexed by total segmented volume) using Bayesian model selection.

Results Data were collected at baseline $(n=116), 12$ months $(n=97)$ and 24 months $(n=84)$ after baseline. Findings demonstrated that the development of most regional gray matter volume, and white matter tract measures, were best modelled by age. Interestingly, precentral and paracentral regions of the cortex, as well as the accumbens demonstrated significant preference for the pubertal status model. None of the white matter tract measures were better modelled by pubertal status.

Limitations: The major limitation of this study is the two-cohort recruitment. Although this allowed a faster coverage of the age span, a complete per person trajectory over 6 years of development (9-15 years) could not be investigated.

Conclusions Comparing the impact of age and pubertal status on regional gray matter volume and white matter tract measures, we found age to best predict longitudinal changes. Further longitudinal studies investigating the differential influence of puberty status and age on brain development in more diverse samples are needed to replicate the present results and address mechanisms underlying norm-variants in brain development.
\end{abstract}

Keywords Adolescent brain development $\cdot$ Puberty $\cdot$ Age $\cdot$ Magnetic resonance imaging (MRI) - Gray matter volume . White matter tracts

\section{Introduction}

Adolescence is a critical period of brain development. Structural and functional interconnectivity of brain regions form a reliably and accurately functioning network to efficiently process information and behavioural output. The development of the brain during adolescence has predominantly

Supplementary Information The online version contains supplementary material available at https://doi.org/10.1007/s0042 9-020-02208-1.

Julian Koenig

julian.koenig@med.uni-heidelberg.de

Extended author information available on the last page of the article been studied in relation to age (Andersen 2003; Blakemore 2012; Giedd and Rapoport 2010; Lenroot and Giedd 2006; Mills and Tamnes 2014). During normative gray matter development, a reduction in general cortical volume with increasing age has been consistently reported (Ducharme et al. 2016; Mills et al. 2016; Vijayakumar et al. 2016; Wierenga et al. 2014). However, more recently, studies have highlighted that the influence of pubertal maturation-not only age - on brain growth is crucial in disentangling the underlying physiological mechanisms (Kaczkurkin et al. 2018).

When considering the effect of age and pubertal status on brain development, it is important to note that the age in which biological changes occur in association with puberty 
varies across individuals. Therefore, age and pubertal status need to be considered as partially distinctive measures. For example, variation in puberty onset can differ by up to 4-5 years (Parent et al. 2003). More recent studies have hence examined the effects of pubertal status on brain development, which has also been recently reviewed (Mills and Tamnes 2014; Vijayakumar et al. 2018). Existing findings suggest that although pubertal status is associated with overall brain development and maturation, particularly in the frontal cortex, findings are inconsistent potentially due to disparities in study designs and measures used. Moreover, previous studies investigating white matter tract development in association with pubertal status are scarce. Consequently, it is still unclear how both age and/or pubertal development are associated with individual trajectories of specific regional brain development.

The present study sought to investigate individual trajectories in brain development comparing the influence of age and pubertal status with a longitudinal design of repeated within-subject measurements during adolescence. More specifically, we aimed to describe longitudinal changes in regional gray matter volume and white matter tract measures modelled by normative physical growth, age, or pubertal status in healthy adolescents tracked over 3 years.

\section{Methods}

\section{Study design and recruitment}

The study was approved by the human research ethics committee of the Medical Faculty at Heidelberg University, Germany (study ID: S-604/2011). All participants and at least one legal guardian signed written informed consent prior to inclusion in the study. Recruitment took place in Heidelberg, Germany in 2014 and 2015. Children were recruited from the general public using letters sent out to households $(n=2398)$ with children within the age range of interest, identified by contacting the citizens registration office at Heidelberg City Council, Germany.

Participants with a history of psychiatric diagnosis or treatment, developmental disorders, premature birth (birth weight below $2000 \mathrm{~g}$ and/or birth before 36th week of pregnancy), intellectual impairment (i.e., IQ $<80$ ), poor knowledge of the German language, or those reporting endocrine disorders were excluded. Adolescents were also excluded if either of their parents had a history of psychiatric diagnosis or treatment. Exclusion criteria also included MRI safety regulations, in which participants reporting claustrophobia, those with metal implants, a history of brain injury, or vascular/neurological diseases (i.e., pathology that may influence brain function) were excluded.
After a screening interview, participants subsequently underwent a structured assessment (detailed below). Participants who agreed to undergo MRI scanning were invited to the Division of Radiology at the German Cancer Research Center, Germany, for a second appointment (detailed below). To capture 6 years of normative brain development, two cohorts of healthy children and adolescents were recruited: a) cohort 1 , which consisted of 9-10 years old and b) cohort 2 , which consisted of 12-13 years old at baseline. These children and adolescents were subsequently followed-up every year until 2 years after the initial scan, making a total of three time-points. Further details on participant flow and reasons for the exclusion of subjects are provided elsewhere (Mürner-Lavanchy et al. 2020).

\section{Structured assessments}

The first assessment consisted of interviews to collect data on demographics, pubertal status using the Pubertal Development Scale (Petersen et al. 1988). The PDS is a selfreport measure composed of 5 items. Three general items (for boys and girls) assess growth spurts, changes in body hair, and skin. Each of these is rated on a 5-point scale: "not yet started", "barely started", "definitely started", "seems complete", and "I don't know" (treated as missing). Girls are further asked to indicate breast growth and onset of menstruation. Boys are asked to indicate changes in voice and facial hair growth. Puberty status is indicated on a 5-point scale (prepubertal, early pubertal, mid pubertal, late pubertal, and post pubertal). Intelligence level was assessed using the General Ability Index (GAI; (Raiford et al. 2005), which is a compressed measure of general intellectual ability measured by the German version of the Wechsler Intelligence Scale for Children, fourth edition (Petermann and Petermann 2008; Wechsler 2003). Psychiatric health of the participants was confirmed using the German version of the Mini-International Neuropsychiatric Interview for Children and Adolescents (M.I.N.I- KID 6.0) (Sheehan et al. 2010). All interviews were performed by trained clinicians in the field of child and adolescent psychiatry.

\section{Neuroimaging}

MRI data were acquired using a Siemens 3 T Biograph mMR with a 16-channel head coil with a total acquisition time of $45 \mathrm{~min}$. Anatomical T1-weighted images were acquired in the sagittal plane (192 slices, $1 \mathrm{~mm}$ slice thickness, $1 \times 1$ $\mathrm{mm} 2$ in-plane resolution, echo time $(\mathrm{TE})=2.98 \mathrm{~ms}$, repetition time $(\mathrm{TR})=2300 \mathrm{~ms}$, and flip angle $=9$ ). A wholebrain single-shot spin-echo echo-planar imaging sequence was used to obtain the DTI images using the following parameters in axial plane: 50 slices, 64 directions, voxel size $=2.5 \mathrm{~mm}$ isotropic, $\mathrm{TE}=112 \mathrm{~ms}, \mathrm{TR}=12,100 \mathrm{~ms}$, 
FOV $=240 \mathrm{~mm}$, matrix size $=96 \times 96$, and $\mathrm{b}$ values at 0 , 1000 and $3000 \mathrm{~s} / \mathrm{mm}$ ). A GeneRalised Autocalibrating Partially Parallel Acquisition (GRAPPA) factor 2 was used.

Automated methods were used for calculating both gray matter volume and white matter tract measures. Each T1 and DTI image was visually checked for quality assurance by trained researchers before automated processing. Participants with abnormal scan reports or with movements of more than $2 \mathrm{~mm}$ were discarded from further analyses. Subsequent to analyses, outputs were overlapped onto native $\mathrm{T} 1$ image for additional quality assurance. For structural segmentation to calculate gray matter volumes, FreeSurfer version 6.0 was used to segment T1-weighted images (Fischl 2012). Details of FreeSurfer segmentation are described in previous papers by Fischl et al. (Fischl et al. 2002, 2004). Outputs from regions listed in the Desikan-Killiany-Tourville atlas were used (Klein and Tourville 2012). For calculating fractional anisotropy (FA) and mean diffusivity (MD) measures of the white matter tracts, DTI data were processed using TRACULA (TRActs Constrained by UnderLying Anatomy, FreeSurfer). This automated method includes pre-processing such as standard methods for image distortion correction of eddy currents and subject movement (Andersson and Sotiropoulos 2016) and B0 field inhomogeneity, intra-subject and inter-subject registration, and tensor fitting as detailed in previous papers (Yendiki 2011; Yendiki et al. 2014). As part of the FreeSurfer suite, TRACULA uses not only anatomical priors derived from an atlas, but also the cortical parcellation and subcortical segmentations derived from native space of each subject in FreeSurfer, allowing individual variations across subjects while still establishing the same tracts for comparison (Jbabdi et al. 2007).

\section{Statistical analyses}

A total of five multi-level linear regression models were calculated for each outcome of interest and compared to a null model $\left(\mathrm{M}_{0}\right)$ using Bayesian model selection. The null model only included total segmented volume as fixed factor to predict regional brain volume or the white matter tract measure of interest (dependent variables). The four models of interest were composed as follows: Model $1\left(\mathrm{M}_{1}\right)$ : fixed factor age (exact age at the time of the scan including 6 decimals); Model $2\left(\mathrm{M}_{2}\right)$ : fixed factor puberty status; Model $3\left(\mathrm{M}_{3}\right)$ : both age and puberty status as fixed factors; Model $4\left(\mathrm{M}_{4}\right)$ : age and pubertal status main and interaction effects. All models included sex as a covariate and subject as random effect. Total segmented volume was added as additional covariate for all models of interest $\left(\mathrm{M}_{1}\right.$ to $\left.\mathrm{M}_{4}\right)$ to control for global effects of brain size (e.g., O'Brien et al. 2011; Peelle et al. 2012 Each model $\left(M_{1}\right.$ to $\left.M_{4}\right)$ was compared to the null model $\left(\mathrm{M}_{0}\right)$ using Bayesian Information Criterion (BIC) differences as an estimation of the Bayes Factor (BF).
Interpretation of the $\mathrm{BF}$ was based on the proposed convention by (Raftery et al. 1995). Beta values for fixed factors correcting for covariates were calculated to illustrate the direction in developmental trajectories based on methods outlined by Hox (1995). For the sake of completeness, we also report on global brain effects All statistical analyses were performed using Stata version 15 (StataCorp 2017).

\section{Results}

\section{Sample characteristics}

After screening interested participants $(n=228), n=125$ met the inclusion criteria. Data were collected at three timepoints at baseline (time-point 1; interview: $n=125$; MRI: $n=114$ ), 12 months from baseline (time-point 2; interview: $n=111$; MRI: $n=94$ ), and 24 months from baseline (timepoint 3; interview: $n=106$; MRI: $n=80$ ). Reasons for dropouts throughout the three time-points included claustrophobia during MRI scan, which was otherwise unknown prior to the MRI scanning session $(n=2 ; 1.6 \%)$, termination of scan due to headache, dizziness of feeling sick $(n=7 ; 5.6 \%)$, withdrawal due to loss of interest $(n=9 ; 7.2 \%)$, no show for appointments $(n=6 ; 4.8 \%)$, or when the participants and their parent were no longer contactable $(n=2 ; 1.6 \%)$. The numbers of participants' MRI data specified in the results demonstrate the final number of MRI data used in the analyses, which excludes images that contained large movement or other artefacts associated with image acquisition $(n=6$; $4.8 \%)$, or artefacts caused by dental braces $(n=13 ; 10.4 \%)$. Summary of demographic information on the cohorts is given in Table 1.

\section{Model comparisons}

When testing for global effects on total segmented volume, we found no superior model fit for age $\left(\mathrm{M}_{1}\right.$ : BIC: - 5.64; BF: 0.06; Prob: 0.05); pubertal status $\left(\mathrm{M}_{2}\right.$ : BIC: - 5.35; BF: 0.07; Prob: 0.06); both main effects $\left(\mathrm{M}_{3}\right.$ : BIC: - 10.93; BF: 0.00; Prob: 0.00); or their interaction $\left(\mathrm{M}_{4}\right.$ : BIC: -13.04 ; BF: 0.00; Prob: 0.00) against a null model (sex only; $\mathrm{M}_{0}$ : BIC: 0.00; BF: 1.00; Prob: 0.88). For region-specific models, model $4\left(\mathrm{M}_{4}\right.$ : age and pubertal status interaction as fixed factor) was not the preferred model for any of the model comparisons, as indicated by model fit comparisons. Therefore, $\mathbf{M}_{4}$ was removed from all subsequent model comparisons. Model comparison for regional gray matter volumes demonstrated that model preference was distributed throughout the brain. Cortical and subcortical regions that were tested, as well as their preferred model are reported in Fig. 1a, with full reports on BIC difference, the BF, and the respective probability 
Table 1 Demographic information of participants who were included in the MRI analysis.

\begin{tabular}{|c|c|c|c|}
\hline & & Cohort $1^{\mathrm{a}}$ & Cohort $2^{b}$ \\
\hline \multirow[t]{5}{*}{ Baseline } & $n$ (females) & $55(26)$ & $59(30)$ \\
\hline & Mean age (SD) & $\begin{array}{l}9.61(0.34) \\
{[8.85-10.29]}\end{array}$ & $\begin{array}{l}12.62(0.32) \\
{[11.86-13.03]}\end{array}$ \\
\hline & Puberty status (SD) & $\begin{array}{l}1.4(0.60) \\
{[1-3]}\end{array}$ & $\begin{array}{l}2.81(0.99) \\
{[1-4]}\end{array}$ \\
\hline & Total segmented volume ${ }^{\mathrm{c}}(\mathrm{SD})$ & $\begin{array}{l}1179287(107546.2) \\
{[947801-1464491]}\end{array}$ & $\begin{array}{l}1191869(108286.7) \\
{[975723-1420689]}\end{array}$ \\
\hline & IQ (HAWIK-GAI) & $\begin{array}{l}119.49(13.45) \\
{[92-148]}\end{array}$ & $\begin{array}{l}117.92(11.64) \\
{[87-146]}\end{array}$ \\
\hline \multirow[t]{5}{*}{12 months } & $n$ (females) & $48(22)$ & $46(21)$ \\
\hline & Mean age (SD) & $\begin{array}{l}10.81(0.38) \\
{[9.93-11.39]}\end{array}$ & $\begin{array}{l}13.85(0.43) \\
{[12.94-14.86]}\end{array}$ \\
\hline & Puberty status (SD) & $\begin{array}{l}1.75(0.76) \\
{[1-3]}\end{array}$ & $\begin{array}{l}3.28(0.89) \\
{[1-5]}\end{array}$ \\
\hline & Total segmented volume ${ }^{\mathrm{c}}(\mathrm{SD})$ & $\begin{array}{l}1196196(106075.1) \\
{[938994-1439917]}\end{array}$ & $\begin{array}{l}1191269(103432.8) \\
{[986087-1414269]}\end{array}$ \\
\hline & Days since baseline (SD) & $\begin{array}{l}413.53(65.61) \\
{[279-579]}\end{array}$ & $\begin{array}{l}415.33(62.91) \\
{[333-611]}\end{array}$ \\
\hline \multirow[t]{5}{*}{24 months } & $n$ (females) & $41(17)$ & $39(17)$ \\
\hline & Mean age (SD) & $\begin{array}{l}11.80(0.38) \\
{[10.97-12.50]}\end{array}$ & $\begin{array}{l}14.86(0.41) \\
{[14.21-16.01]}\end{array}$ \\
\hline & Puberty status (SD) & $\begin{array}{l}2.10(0.80) \\
{[1-3]}\end{array}$ & $\begin{array}{l}3.51(0.85) \\
{[1-5]}\end{array}$ \\
\hline & Total segmented volume ${ }^{\mathrm{c}}(\mathrm{SD})$ & $\begin{array}{l}1187069(99999.5) \\
{[988972-1393745]}\end{array}$ & $\begin{array}{l}1193478(113822.7) \\
{[988529-462798]}\end{array}$ \\
\hline & Days since 12 months (SD & $\begin{array}{l}342.90(75.70) \\
{[210-676]}\end{array}$ & $\begin{array}{l}358.54(97.06) \\
{[214-737]}\end{array}$ \\
\hline
\end{tabular}

$S D$ standard deviation; range: in square brackets; $I Q$ intelligence quotient; HAWIK-GAI HamburgWechsler Intelligenztest für Kinder-General Ability Index.

${ }^{a}$ Cohort $1,9-10$ years old at baseline

${ }^{\mathrm{b}}$ Cohort 2, 12-13 years old at baseline

${ }^{\mathrm{c}}$ Total segmented volume presented in $\mathrm{mm}^{3}$ of comparisons in the Supplementary Material. Cortices that showed the null model $\left(\mathrm{M}_{0}\right)$ as the best fitting model included cerebellum, lateral and medial orbitofrontal, pars orbitalis, entorhinal, interior temporal, rostra anterior cingulate cortices, and subcortical regions such as the insula and the parahippocampal gyrus. As illustrated in Fig. 1a, the preferred model and its representation on the brain, most regional gray matter volumes were best modelled by age $\left(\mathrm{M}_{1}\right)$. These included regions of the frontal cortex, parietal cortex, occipital cortex, temporal cortex, the cingulate cortex and subcortically the amygdala, hippocampus, caudate, pallidum, and putamen. Regional gray matter volumes that were best modelled by pubertal status $\left(\mathrm{M}_{2}\right)$ included the precentral region, paracentral lobule, pericalcarine sulcus, and subcortically the accumbens. The postcentral region was the only gray matter region best modelled with the addition of both age and pubertal status as fixed factors $\left(\mathrm{M}_{3}\right)$. Graphical representations of the preferred model predicting gray matter development are provided in Fig. 1a. Beta values for the fixed factors of each model are presented in Fig. $1 b$.

FA and MD of the white matter tracts tested and the preferred model for each measure is indicated in Fig. 2. Full reporting on BIC difference, the BF and the respective probability of the comparisons is provided in the Supplementary Material. The corpus callosum-forceps minor-as well as the FA of the inferior longitudinal fasciculus and uncinate fasciculus were best modelled by general brain size indicated by total segmented volume $\left(\mathrm{M}_{0}\right)$. Once more, age was the preferred model $\left(\mathrm{M}_{1}\right)$ for a majority of the tracts including MD and FA of the anterior thalamic radiations, both parietal and temporal endings of the superior longitudinal fasciculus, cingulum - angular bundle, cingulum - cingulate gyrus endings, as well as MD of the inferior longitudinal fasciculus, uncinate fasciculus, corpus callosum-forceps major and cortico-spinal tract. FA of the corpus callosum-forceps major and the cortico-spinal tract were the only white matter tract measures that were best modelled with the addition of 

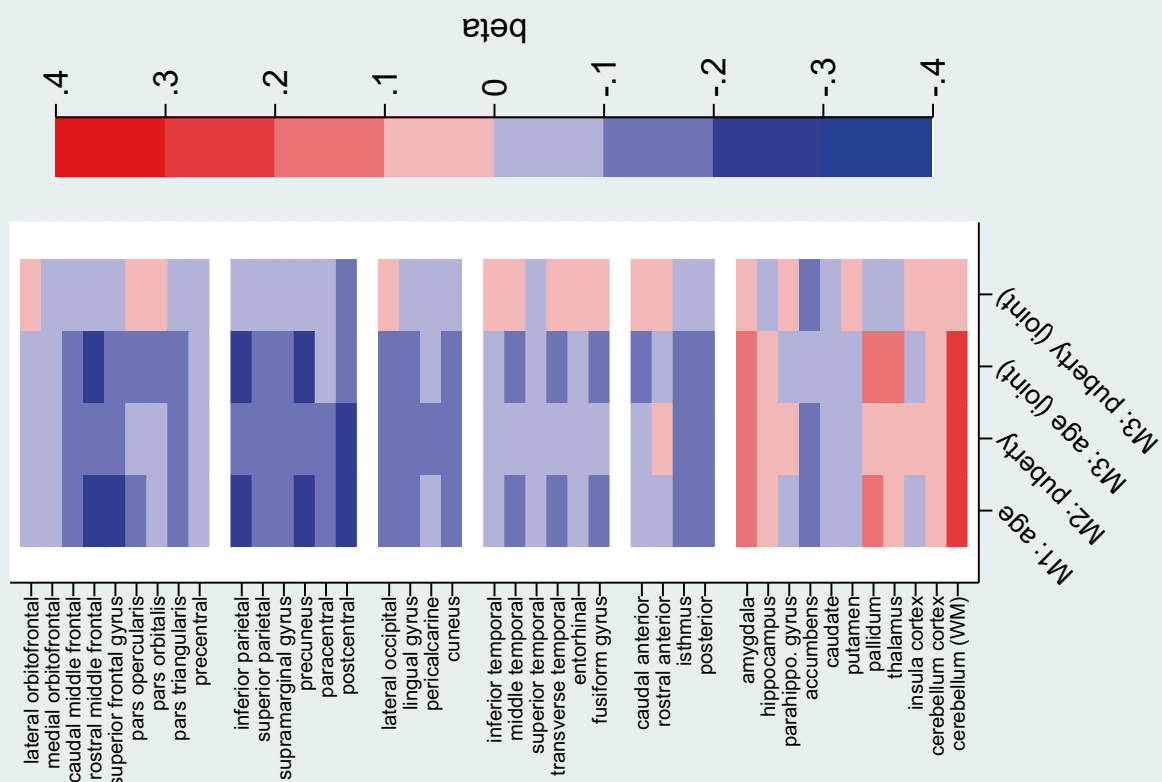

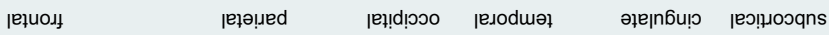

$m$

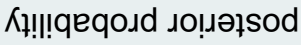
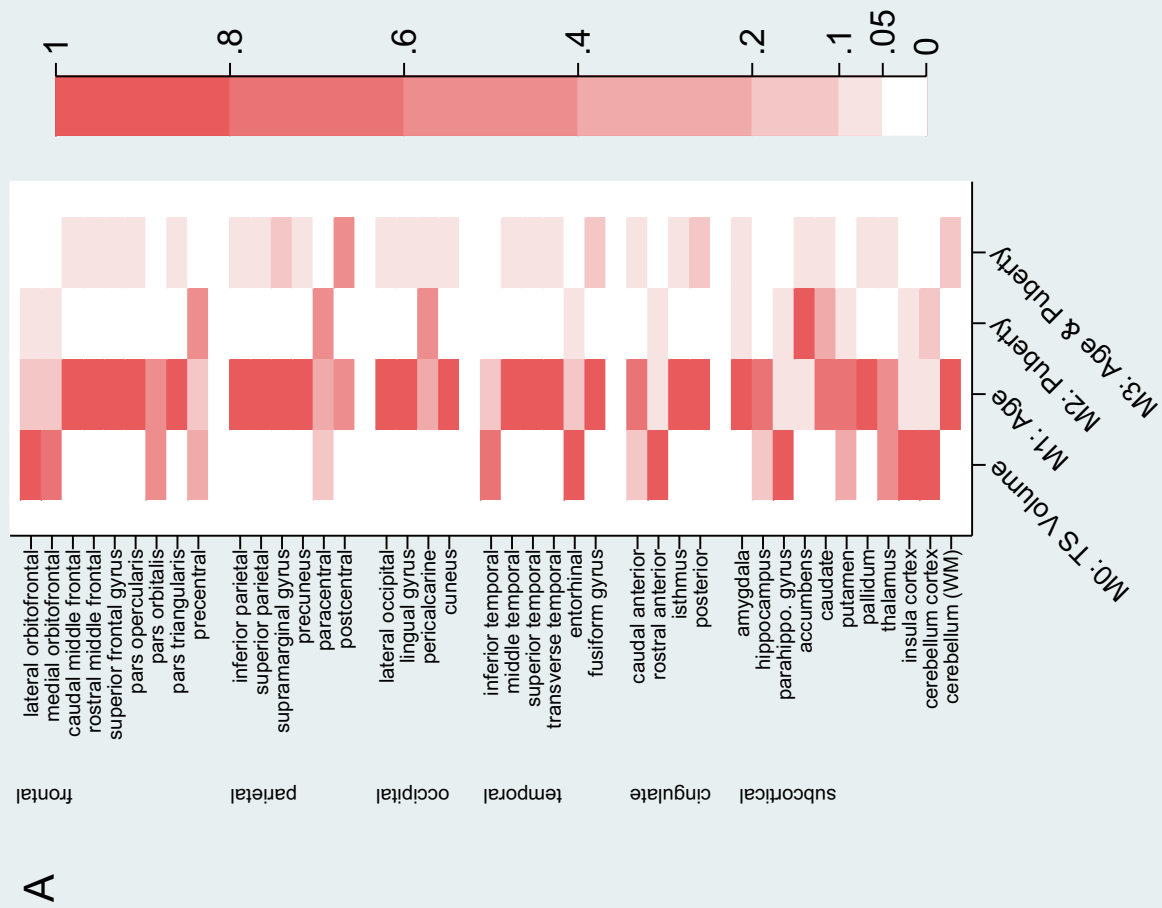


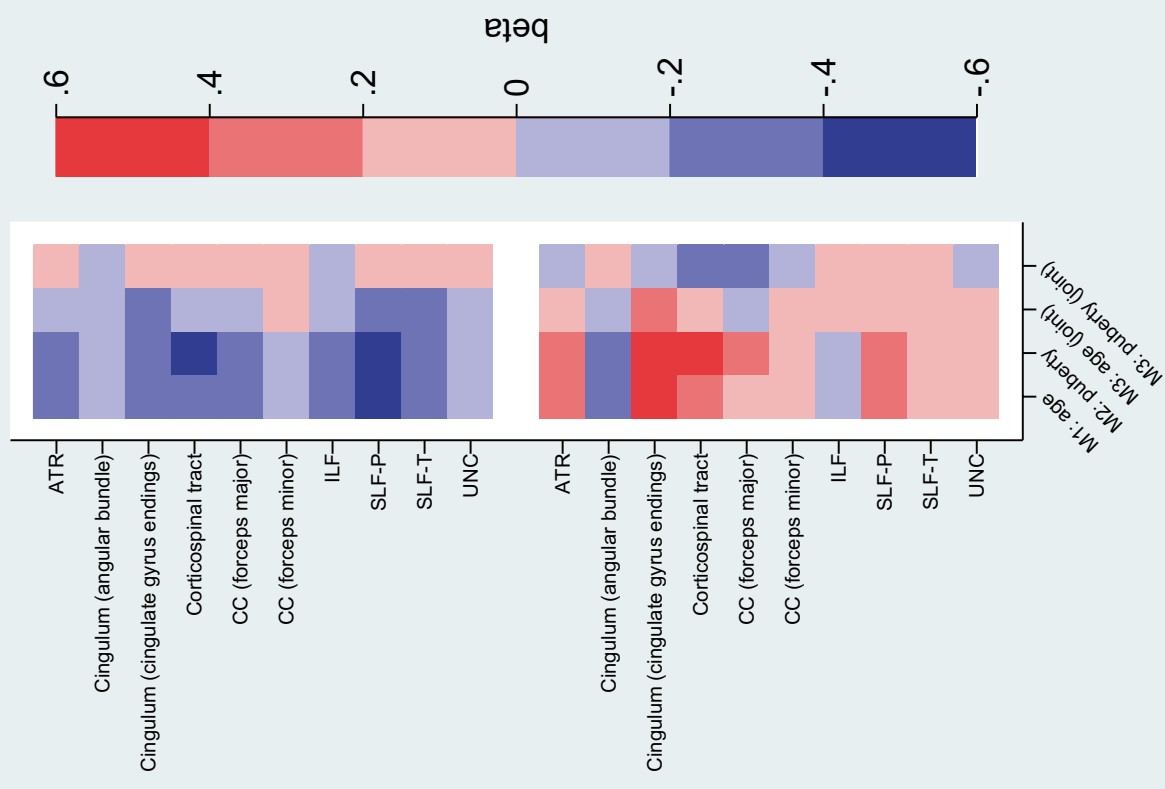

К!!ก!̣รnщ!p ueəu

Kdoגłos!̣ue ןeuo!̣’eมł

$m$

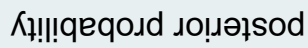

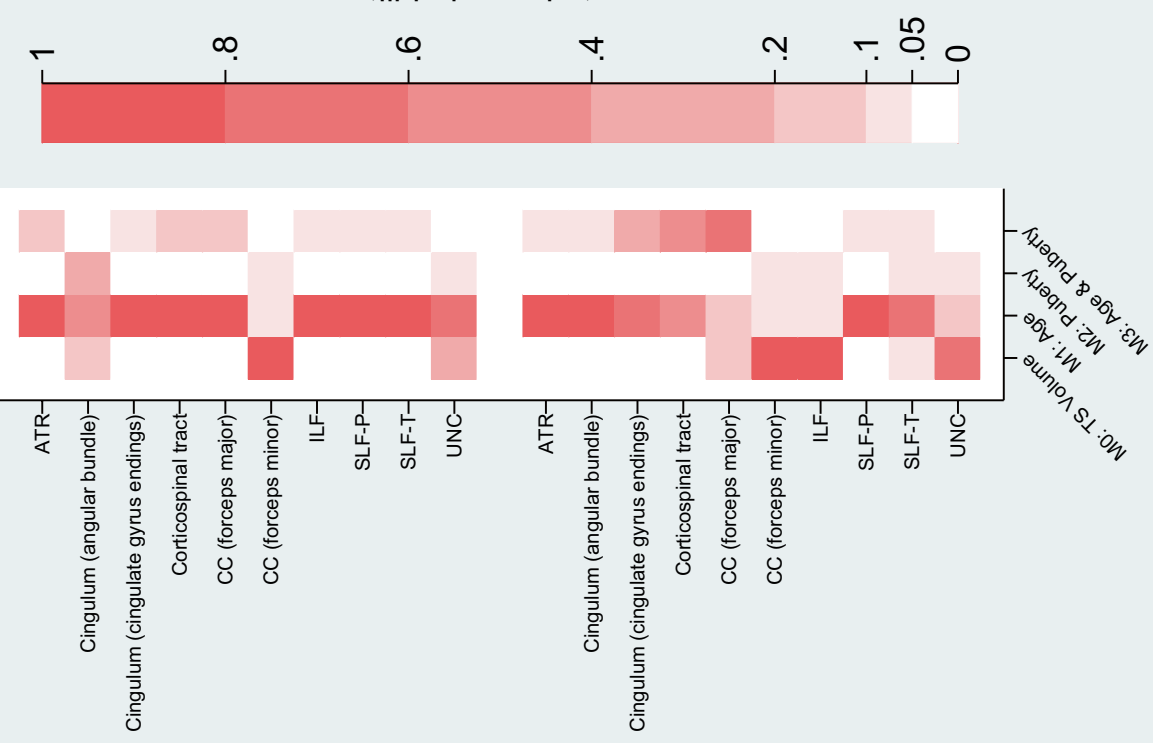

Кł!ก!ฺsกщ!p иеәш

Kdoגłos!̣ue ןeuo!̣эeגf

$\varangle$

实安总

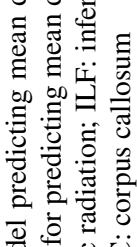

웡.

氖啳

पे $\dot{\Sigma} \cdot \frac{0}{0}$

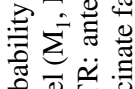

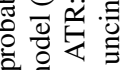

它至荃

过

ฉे

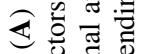

密

$\cong$ 氜

产艺近

茪.气

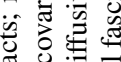

훙

氖 $\stackrel{0}{\Xi}$.

苍完

守的

उ苛言离

㐘苛

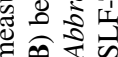

में

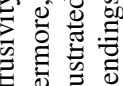

帠

寻实

过 $\dot{s}$

急导兽

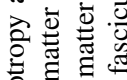

(1)

光坣坣

편

\&े के

奇言

垴 导

这合

क्ष

圆高㟔

흐 สำ

胥

可焉

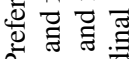


both age and pubertal status as fixed factors $\left(\mathrm{M}_{3}\right)$. Pubertal status as fixed factor $\left(\mathrm{M}_{2}\right)$ was not the preferred model predicting FA and MD measures from any of the white matter tracts under investigation. Graphical representations of the preferred model predicting white matter tract development are provided in Fig. 2a. Beta values for the fixed factors of each model are also presented in Fig. 2 b.

\section{Discussion}

The present study compared the influence of age and pubertal status on the longitudinal trajectory of structural brain development in adolescents. Following an exploratory approach, we addressed the impact of age and puberty status on gray matter volume in 39 regions of interest and 10 white matter tracts. Given the plenitude of statistical tests, we relied on Bayesian statistics to minimize potential error associated with multiple testing under a frequentist framework. Analyses demonstrated that the development of gray matter volume and white matter tracts during adolescence is overall best predicted by age. Interestingly, Bayesian model selection revealed that gray matter volume development in precentral and paracentral regions of the cortex, as well as subcortical regions including the accumbens are better predicted by pubertal status. None of the white matter tract measures were better modelled by pubertal status, but FA values of the corpus callosum (forceps major) and corticospinal tract were better predicted by the addition of both age and pubertal status as fixed factors in a joint model.

Previous studies investigating the effects of pubertal status on gray matter development have shown negative associations between global gray matter volume and pubertal status, as well as gonadal hormone levels (Bramen et al. 2011; Paus et al. 2010; Peper, Brouwer, et al. 2009a, b; Pfefferbaum et al. 2016). Other studies have shown no significant relationship between gray matter volume and puberty-associated changes (Brouwer et al. 2015). The most consistent regional finding to date has been the association between pubertal status and the development of frontal and temporal lobes, as well as the anterior cingulate cortex in both cross-sectional and longitudinal studies (Bramen et al. 2012; Herting et al. 2015; Hu et al. 2013; Koolschijn et al. 2014; Nguyen et al. 2013a, b; Peper, Schnack et al. 2009a, b; Pfefferbaum et al. 2016). Interestingly, however, the results observed in the current study of longitudinal development showed that most of these regions are, however, better modelled by age rather than pubertal status, with most regions showing a negative association indicating a general decrease in gray matter volume with increasing age.

Additionally, the amygdala and hippocampus have consistently been highlighted as subcortical regions of interests when investigating brain development during puberty due to the dense population of sex steroid hormone receptors in these regions (Abdelgadir et al. 1999). The current study investigated not only the amygdala and hippocampus, but a wider network of subcortical regions including the parahippocampal gyrus, accumbens, caudate, putamen, pallidum, and thalamus. Amygdala volume has been shown to have a negative association with female pubertal status, but a positive association with male pubertal status (Blanton et al. 2012; Hu et al. 2013). Hippocampus volume has also revealed a negative association with pubertal status (Blanton et al. 2012; Neufang et al. 2009), but with two studies showing sexual dimorphic patterns (Bramen et al. 2012; Hu et al. 2013). Interestingly, the amygdala and hippocampus did not show preference for pubertal status in the current study but rather the accumbens. In animal studies, the accumbens has been shown to be related to the dopaminergic pathways associated with pubertal hormonal changes, such that there is increased motivation for reward seeking behaviour including sexual behaviour (Sato et al. 2008). However, the distinct association of pubertal alteration in the accumbens in humans is still unclear and further longitudinal studies building on the present findings are needed.

Moreover, our analyses showed that neither FA nor MD of any of the tracts that were tested showed significant preference for the pubertal status model. However, previous research investigating white matter tract development in association with pubertal status has been scarce. While some studies implicate a predominantly positive association between pubertal status and FA (Herting et al. 2012; Menzies et al. 2015), only a few studies have observed any association with pubertal status and MD (Menzies et al. 2015). The few studies that investigated such association found similarities to findings on gray matter volume development, where cortico-cortico and cortico-subcortical tracts that are associated with the frontal and temporal lobes showed the most consistent associations with pubertal status (Herting et al. 2012; Menzies et al. 2015). In the current study, however, cortico-spinal and hemispheric connections were associated with age and pubertal status, where FA of both of these tracts were negatively associated with age and pubertal status. Most interestingly, beta values indicated that when both age and pubertal status are added as fixed factor in a joint model, FA has a positive association with age and a negative association with pubertal status. This finding highlights a potential role of cortico-spinal and hemispheric connections in studying norm-variants in delayed or premature pubertal development. Additional studies in more diverse samples are needed to ascertain and disentangle the intertwining influences of age and pubertal status in these regions of interest.

Inconsistencies seen with previous studies could be influenced by the various measures of pubertal status used. For example, there are two prominent systems for measuring 
pubertal status: the Tanner Stage (Tanner, 1692), and the PDS (Petersen et al. 1988). The two measures are not correlated, and therefore, they are potentially capturing differential aspects of pubertal development. The current study used the PDS (Petersen et al. 1988), and due to its selfreport format, it could be considered as one of the limitations of the study, potentially introducing bias (Shirtcliff et al. 2009). Although the study design could improve by the addition of physical examination, we opted out of this option due to its intrusiveness. Another reason for inconsistent associations seen with brain development and puberty could be due to some studies using hormone measures as an indicator of pubertal development. Although hormones are a direct measure of pubertal maturation, there is unfortunately a wide range of variability in hormone levels during adolescence and its associated pubertal stages of development (Dorn et al. 2004; Dorn and Biro 2011). For example, hormone levels vary according to the time of day the sample is obtained, the menstrual cycle in females, diet, stress, and other environmental factors. Furthermore, differential collection and analysis methods, such as saliva, blood, and urine samples, have also produced varying results (Vesper et al. 2014). Measuring hormone levels from hair could provide a more stable measure in this regard.

One major pitfall of the present study is the two-cohort design that was applied to facilitate the recruitment process. Although this allowed a faster collection of data with a larger age range, a complete within-subject trajectory over 6 years could not be investigated. Therefore, we were only able to investigate the trajectory from three time-points for two cohorts rather than six time-points for the entire sample. The age of data collection is a crucial aspect for a study on longitudinal developmental. Past neuroimaging studies investigating gray matter development have reported widespread alterations in the cortex during adolescence. For example, an inverted U-shaped developmental pattern, peaking at various ages in different cortices, has been reported from studies using the National Institute of Mental Health Child Psychiatry dataset in males and females aged between 4 and 25 years (Giedd et al. 1999; Lenroot and Giedd 2006; Raznahan et al. 2014). However, other studies report a linear decrease in total gray matter volume across late childhoodto-adulthood, where the greatest proportion and highest rate of decrease in gray matter volume occurred in participants in their teens and no significant change was seen in participants aged between 22 and 32 years (Lebel and Beaulieu 2011; Tamnes et al. 2013; Wierenga et al. 2014). Another study showed stable volumes of gray matter up to 10 years old, and then, a decrease was observed between ages 10 and 20 (Aubert-Broche et al. 2013). These heterogeneous findings indicate that although there may not be a clear age of "peak" of gray matter volume, it reaches its maximum during late childhood and decreases throughout adolescence to adulthood, where volume loss decelerates. The current three timepoints from ages 9 and 12 may not have best captured the peak of development. One advantage of the present study is that an automated method has been used to calculate both volume and white matter tract information, allowing fast, reliable, and easily reproducible results, which also reduces the risk of manual error or bias depending on the researcher. Moreover, the outputs from volumetric comparisons were used to compute white matter tract information, allowing the tract calculation to be completed in native space. However, given the focus on gray matter volume and white matter tracts, we did not assess other brain structural variables of potential interest such as surface area and cortical thickness. Finally, our sample represents a high-function group of individuals, as further reflected in the high average IQ scores, way beyond what would be expected for the norm. While likely linked to specifics in the regional catchment area, it is not clear how the present findings generalize to samples from a diverse educational or socioeconomic background.

To summarize, the present study highlights some regions of interest, which-alongside the majority of brain regions that are best predicted by age in their development-are driven in their development across adolescence by pubertal status. Further longitudinal studies are needed to replicate the findings in more diverse and larger samples across the pubertal age span. These studies could be improved by incorporating gonadal hormone measures in combination with physical examinations of pubertal stats. Furthermore, the addition of functional MRI and measures of socioenvironmental factors would aid our understanding on the physical development and associated changes in functional activity and connectivity.

Acknowledgements This work was supported by the Dietmar Hopp Foundation of Baden-Württemberg, Germany. We would also like to acknowledge the work by Julia Völker for her support in participant recruitment and data collection.

Funding Open Access funding enabled and organized by Projekt DEAL.. The study was funded by the Dietmar Hopp Foundation of Baden-Württemberg, Germany (Grant number: 23011197).

Data availability The datasets generated during and/or analysed during the current study are available from the corresponding author on reasonable request.

\section{Compliance with ethical standards}

Conflict of interest The authors have no conflict of interest to declare.

Ethical approval The study was approved by the human research ethics committee of the Medical Faculty at Heidelberg University, Germany (study ID: S-604/2011). 
Informed consent All participants and at least one legal guardian signed written informed consent prior to inclusion in the study.

Open Access This article is licensed under a Creative Commons Attribution 4.0 International License, which permits use, sharing, adaptation, distribution and reproduction in any medium or format, as long as you give appropriate credit to the original author(s) and the source, provide a link to the Creative Commons licence, and indicate if changes were made. The images or other third party material in this article are included in the article's Creative Commons licence, unless indicated otherwise in a credit line to the material. If material is not included in the article's Creative Commons licence and your intended use is not permitted by statutory regulation or exceeds the permitted use, you will need to obtain permission directly from the copyright holder. To view a copy of this licence, visit http://creativecommons.org/licenses/by/4.0/.

\section{References}

Abdelgadir SE, Roselli CE, Choate JVA, Resko JA (1999) Androgen receptor messenger ribonucleic acid in brains and pituitaries of male rhesus monkeys: studies on distribution, hormonal control, and relationship to luteinizing hormone secretion1. Biol Reprod 60:1251-1256. https://doi.org/10.1095/biolreprod60.5.1251

Andersen SL (2003) Trajectories of brain development: point of vulnerability or window of opportunity? Neurosci Biobehav Rev 27(1-2):3-18. https://doi.org/10.1016/S0149-7634(03)00005-8

Andersson JLR, Sotiropoulos SN (2016) An integrated approach to correction for off-resonance effects and subject movement in diffusion MR imaging. NeuroImage 125:1063-1078. https://doi. org/10.1016/j.neuroimage.2015.10.019

Aubert-Broche B, Fonov VS, García-Lorenzo D, Mouiha A, Guizard N, Coupé P, Eskildsen SF, Collins DL (2013) A new method for structural volume analysis of longitudinal brain MRI data and its application in studying the growth trajectories of anatomical brain structures in childhood. NeuroImage. https://doi. org/10.1016/j.neuroimage.2013.05.065

Blakemore SJ (2012) Imaging brain development: the adolescent brain. NeuroImage. https://doi.org/10.1016/j.neuroimage .2011.11.080

Blanton RE, Cooney RE, Joormann J, Eugène F, Glover GH, Gotlib IH (2012) Pubertal stage and brain anatomy in girls. Neuroscience 217:105-112. https://doi.org/10.1016/j.neuroscien ce.2012.04.059

Bramen JE, Hranilovich JA, Dahl RE, Chen J, Rosso C, Forbes EE, Dinov ID, Worthman CM, Sowell ER (2012) Sex matters during adolescence: Testosterone-related cortical thickness maturation differs between boys and girls. PLoS ONE. https://doi. org/10.1371/journal.pone.0033850

Bramen JE, Hranilovich JA, Dahl RE, Forbes EE, Chen J, Toga AW, Dinov ID, Worthman CM, Sowell ER (2011) Puberty influences medial temporal lobe and cortical gray matter maturation differently in boys than girls matched for sexual maturity. Cereb Cortex 21(3):636-646. https://doi.org/10.1093/cercor/bhq137

Brouwer RM, Koenis MMG, Schnack HG, van Baal GC, van Soelen ILC, Boomsma DI, Hulshoff Pol HE (2015) Longitudinal development of hormone levels and grey matter density in 9 and 12-year-old twins. Behav Genet 45(3):313-323. https://doi. org/10.1007/s10519-015-9708-8

Dorn LD, Biro FM (2011) Puberty and its measurement: a decade in review. J Res Adolesc 21(1):180-195. https://doi.org/10.111 $1 / \mathrm{j} .1532-7795.2010 .00722 . x$

Dorn LD, Dahl RE, Woodward HR, Biro F (2004). Defining the boundaries of early adolescence: a user's guide to assessing pubertal status and pubertal timing in research with adolescents. In Davison \& Susman. Orr \& Ingersoll.

Ducharme S, Albaugh MD, Nguyen TV, Hudziak JJ, Mateos-Pérez JM, Labbe A, Evans AC, Karama S, Ball WS, Byars AW, Schapiro M, Bommer W, Carr A, German A, Dunn S, Rivkin MJ, Waber D, Mulkern R, Vajapeyam S, O'Neill J (2016) Trajectories of cortical thickness maturation in normal brain development - the importance of quality control procedures. NeuroImage 125:267-279. https://doi.org/10.1016/j.neuroimage.2015.10.010

Fischl B (2012) FreeSurfer. NeuroImage 32:774-781. https://doi. org/10.1016/j.neuroimage.2012.01.021

Fischl B, Salat DH, Busa E, Albert M, Dieterich M, Haselgrove C, Van Der Kouwe A, Killiany R, Kennedy D, Klaveness S, Montillo A, Makris N, Rosen B, Dale AM (2002) Neurotechnique whole brain segmentation: automated labeling of neuroanatomical structures in the human brain. Neuron 33:341-355

Fischl B, Van Der Kouwe A, Destrieux C, Halgren E, Ségonne F, Salat DH, Busa E, Seidman LJ, Goldstein J, Kennedy D, Caviness V, Makris N, Rosen B, Dale AM (2004) Automatically parcellating the human cerebral cortex. Cereb Cortex. https:// doi.org/10.1093/cercor/bhg087

Giedd JN, Blumenthal J, Jeffries NO, Castellanos FX, Liu H, Zijdenbos

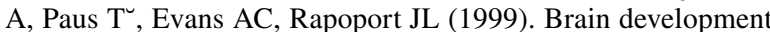
during childhood and adolescence: a longitudinal MRI study. Blackwell Scientific Arch. Gen. Psychiatry Neuroimage Brain Science Int. J. Psychophysiol 51(150): 3-70.

Giedd JN, Rapoport JL (2010) Structural MRI of pediatric brain development: what have we learned and where are we going? Neuron. https://doi.org/10.1016/j.neuron.2010.08.040

Herting MM, Gautam P, Spielberg JM, Dahl RE, Sowell ER (2015) A longitudinal study: changes in cortical thickness and surface area during pubertal maturation. PLoS ONE. https://doi.org/10.1371/ journal.pone.0119774

Herting MM, Maxwell EC, Irvine C, Nagel BJ (2012) The impact of sex, puberty, and hormones on white matter microstructure in adolescents. Cereb Cortex 22(9):1979-1992. https://doi.org/10.1093/ cercor/bhr246

Hox JJ (1995) Applied multi-level analysis. TT-Publikaties.

Hu S, Pruessner JC, Coupé P, Collins DL (2013) Volumetric analysis of medial temporal lobe structures in brain development from childhood to adolescence. NeuroImage 74:276-287. https://doi. org/10.1016/j.neuroimage.2013.02.032

Jbabdi S, Woolrich MW, Andersson JLR, Behrens TEJ (2007) A Bayesian framework for global tractography. Hum Brain Mapp J 37:116-129. https://doi.org/10.1016/j.neuroimage.2007.04.039

Kaczkurkin AN, Raznahan A, Satterthwaite TD (2018) Sex differences in the developing brain: insights from multimodal neuroimaging. Neuropsychopharmacology. https://doi.org/10.1038/s4138 6-018-0111-z

Klein A, Tourville J (2012) 101 labeled brain images and a consistent human cortical labeling protocol. Front Neurosci. https://doi. org/10.3389/fnins.2012.00171

Koolschijn PCMP, Peper JS, Crone EA (2014) The influence of sex steroids on structural brain maturation in adolescence. PLoS ONE. https://doi.org/10.1371/journal.pone.0083929

Lebel C, Beaulieu C (2011) Longitudinal development of human brain wiring continues from childhood into adulthood. J Neurosci 31(30):10937-10947. https://doi.org/10.1523/JNEUR OSCI.5302-10.2011

Lenroot RK, Giedd JN (2006) Brain development in children and adolescents: insights from anatomical magnetic resonance imaging. Neurosci Biobehav Rev 30(6):718-729. https://doi.org/10.1016/j. neubiorev.2006.06.001

Menzies L, Goddings AL, Whitaker KJ, Blakemore SJ, Viner RM (2015) The effects of puberty on white matter development in 
boys. Dev Cogn Neurosci 11:116-128. https://doi.org/10.1016/j. den.2014.10.002

Mills KL, Goddings AL, Herting MM, Meuwese R, Blakemore SJ, Crone EA, Dahl RE, Güroğlu B, Raznahan A, Sowell ER, Tamnes CK (2016) Structural brain development between childhood and adulthood: convergence across four longitudinal samples. NeuroImage. https://doi.org/10.1016/j.neuroimage.2016.07.044

Mills KL, Tamnes CK (2014) Methods and considerations for longitudinal structural brain imaging analysis across development. Dev Cogn Neurosci. https://doi.org/10.1016/j.den.2014.04.004

Mürner-Lavanchy IM, Koenig J, Ando A, Henze R, Schell S, Resch F, Brunner R, Kaess M (2020) Neuropsychological development in adolescents: Longitudinal associations with white matter microstructure. Dev Cogn Neurosci 45:100812. https://doi. org/10.1016/j.den.2020.100812

Neufang S, Specht K, Hausmann M, Güntürkün O, Herpertz-Dahlmann B, Fink GR, Konrad K (2009) Sex differences and the impact of steroid hormones on the developing human brain. Cereb Cortex 19(2):464-473. https://doi.org/10.1093/cercor/bhn100

Nguyen TV, McCracken J, Ducharme S, Botteron KN, Mahabir M, Johnson W, Israel M, Evans AC, Karama S (2013a) Testosteronerelated cortical maturation across childhood and adolescence. Cereb Cortex 23(6):1424-1432. https://doi.org/10.1093/cercor/ bhs 125

Nguyen T-V, McCracken JT, Ducharme S, Cropp BF, Botteron KN, Evans AC, Karama S (2013b) Interactive effects of dehydroepiandrosterone and testosterone on cortical thickness during early brain development. J Neurosci 33(26):10840-10848. https://doi. org/10.1523/jneurosci.5747-12.2013

Parent AS, Teilmann G, Juul A, Skakkebaek NE, Toppari J, Bourguignon JP (2003) The timing of normal puberty and the age limits of sexual precocity. Endocr Rev 24(5):668-693. https://doi. org/10.1210/er.2002-0019

Paus T, Nawaz-Khan I, Leonard G, Perron M, Pike GB, Pitiot A, Richer L, Susman E, Veillette S, Pausova Z (2010) Sexual dimorphism in the adolescent brain: role of testosterone and androgen receptor in global and local volumes of grey and white matter. Horm Behav 57(1):63-75. https://doi.org/10.1016/j.yhbeh.2009.08.004

Peper JS, Brouwer RM, Schnack HG, van Baal GC, van Leeuwen M, van den Berg SM, Delemarre-Van de Waal HA, Boomsma DI, Kahn RS, Hulshoff Pol HE (2009a) Sex steroids and brain structure in pubertal boys and girls. Psychoneuroendocrinology 34(3):332-342. https://doi.org/10.1016/j.psyneuen.2008.09.012

Peper JS, Schnack HG, Brouwer RM, Van Baal GCM, Pjetri E, Székely E, Van Leeuwen M, Van Den Berg SM, Collins DL, Evans AC, Boomsma DI, Kahn R, Hulshoff Pol HE (2009b) Heritability of regional and global brain structure at the onset of puberty: a magnetic resonance imaging study in 9-year-old twin pairs. Hum Brain Mapp 30(7):2184-2196. https://doi.org/10.1002/hbm.20660

Petermann F, Petermann U (2008) HAWIK-IV. Kindheit Und Entwicklung. https://doi.org/10.1026/0942-5403.17.2.71

Petersen AC, Crockett L, Richards M, Boxer A (1988) A self-report measure of pubertal status: reliability, validity, and initial norms. J Youth Adolesc 17(2):117-133

Pfefferbaum A, Rohlfing T, Pohl KM, Lane B, Chu W, Kwon D, Nolan Nichols B, Brown SA, Tapert SF, Cummins K, Thompson WK, Brumback T, Meloy MJ, Jernigan TL, Dale A, Colrain IM, Baker FC, Prouty D, De Bellis MD, Sullivan EV (2016) Adolescent development of cortical and white matter structure in the NCANDA sample: role of sex, ethnicity, puberty, and alcohol drinking. Cereb Cortex 26(10):4101-4121. https://doi. org/10.1093/cercor/bhv205
Raftery AE, Hauser R, Hout M, Lewis S, Long S, Lye D, Marsden P, Western B, Xie Y, David Cox S, DiPrete T, Goldthorpe J, Grusky D, Hoeting J, Kass R, Madigan D, Sobel M, Volinsky C (1995) Bayesian model selection in social research. Source 25:111-163

Raiford SE, Weiss LG, Rolfhus E, Coalson D (2005) General ability index.

Raznahan A, Shaw PW, Lerch JP, Clasen LS, Greenstein D, Berman R, Pipitone J, Chakravarty MM, Giedd JN (2014) Longitudinal fourdimensional mapping of subcortical anatomy in human development. Proc Natl Acad Sci. https://doi.org/10.1073/pnas.13169 11111

Sato SM, Schulz KM, Sisk CL, Wood RI (2008) Adolescents and androgens, receptors and rewards. Horm Behav 53(5):647-658. https://doi.org/10.1016/j.yhbeh.2008.01.010

Sheehan DV, Sheehan KH, Shytle RD, Janavs J, Bannon Y, Rogers JE, Milo KM, Stock SL, Wilkinson B (2010) Reliability and validity of the mini international neuropsychiatric interview for children and adolescents (MINI-KID). J Clin Psychiatry 71(3):313-326. https://doi.org/10.4088/JCP.09m05305whi

Shirtcliff EA, Dahl RE, Pollak SD (2009) Pubertal development: correspondence between hormonal and physical development. Child Dev 80(2):327-337. https://doi.org/10.111 1/j.1467-8624.2009.01263.x

StataCorp. (2017). Statistical Software (No. 14). StataCorp LP.

Tamnes CK, Walhovd KB, Dale AM, Østby Y, Grydeland H, Richardson G, Westlye LT, Roddey JC, Hagler DJ, Due-Tønnessen P, Holland D, Fjell AM (2013) Brain development and aging: overlapping and unique patterns of change. NeuroImage. https:// doi.org/10.1016/j.neuroimage.2012.11.039

Tanner JM (1692) Growth at adolescence. Blackwell Publishing, Oxford

Vesper H, Wang Y, Botelho J (2014) Challenges and improvements in testosterone and estradiol testing. Asian J Androl 16(2):178. https ://doi.org/10.4103/1008-682x.122338

Vijayakumar N, Allen NB, Youssef G, Dennison M, Yücel M, Simmons JG, Whittle S (2016) Brain development during adolescence: a mixed-longitudinal investigation of cortical thickness, surface area, and volume. Hum Brain Mapp. https://doi. org/10.1002/hbm. 23154

Vijayakumar N, Op de Macks Z, Shirtcliff EA, Pfeifer JH (2018) Puberty and the human brain: insights into adolescent development. Neurosci Biobehav Rev. https://doi.org/10.1016/j.neubi orev.2018.06.004

Wechsler D (2003) Wechsler intelligence scale for children-Fourth Edition. The Psychological Coorporation.

Wierenga LM, Langen M, Oranje B, Durston S (2014) Unique developmental trajectories of cortical thickness and surface area. NeuroImage. https://doi.org/10.1016/j.neuroimage.2013.11.010

Yendiki A (2011) Automated probabilistic reconstruction of whitematter pathways in health and disease using an atlas of the underlying anatomy. Front Neuroinform. https://doi.org/10.3389/fninf .2011 .00023

Yendiki A, Koldewyn K, Kakunoori S, Kanwisher N, Fischl B (2014) Spurious group differences due to head motion in a diffusion MRI study. NeuroImage. https://doi.org/10.1016/j.neuroimage .2013.11.027

Publisher's Note Springer Nature remains neutral with regard to jurisdictional claims in published maps and institutional affiliations. 


\section{Authors and Affiliations}

\section{Ayaka Ando ${ }^{1}$. Peter Parzer ${ }^{2} \cdot$ Michael Kaess $^{3,4}$. Susanne Schell ${ }^{2} \cdot$ Romy Henze $^{5,6,7}$. Stefan Delorme ${ }^{8}$. Bram Stieltjes $^{8,9} \cdot$ Franz Resch $^{2} \cdot$ Romuald Brunner $^{10} \cdot$ Julian Koenig ${ }^{1,3}$ (D)}

1 Section for Experimental Child and Adolescent Psychiatry, Department of Child and Adolescent Psychiatry, Centre for Psychosocial Medicine, University of Heidelberg, Blumenstr. 8, 69115 Heidelberg, Germany

2 Clinic for Child and Adolescent Psychiatry, Centre for Psychosocial Medicine, University of Heidelberg, Heidelberg, Germany

3 University Hospital of Child and Adolescent Psychiatry and Psychotherapy, University of Bern, Bern, Switzerland

4 Section for Translational Child and Adolescent Psychiatry, Department of Child and Adolescent Psychiatry, Centre for Psychosocial Medicine, University of Heidelberg, Heidelberg, Germany

5 Department of Psychiatry, Psychotherapy and Psychosomatics, Evangelisches Krankenhaus Königin Elisabeth Herzberge, Berlin, Germany
6 Department of Psychology, Humboldt-Universität zu Berlin, Berlin, Germany

7 Clinical Psychology and Psychotherapy, Freie Universität Berlin, Berlin, Germany

8 Department of Radiology, German Cancer Research Centre, Heidelberg, Germany

9 Department of Radiology and Nuclear Medicine, Universitätsspital Basel, Basel, Switzerland

10 Clinic for Child and Adolescent Psychiatry, Psychosomatics and Psychotherapy, University of Regensburg, Regensburg, Germany 